\title{
2020
}

Author information:

Kzyl Mae S. Albiso

sinfoniastagione.rozk@gmail.com

BS Agricultural and

Biosystems Engineering (2019)

College of Agriculture and

Related Sciences

University of Southeastern Philippines

Tagum-Mabini Campus,

Mabini, Davao de Oro

Ryan M. Abenoja

ryan.abenoja@usep.edu.ph orcid: 0000-0002-2539-5104

Roger C. Montepio

roger.montepio@usep.edu.ph orcid: 0000-0002-3061-1764

Ruel F. Tuyogon

ruel.tuyogon@usep.edu.ph

orcid: 0000-0002-1867-7883

Faculty, Department of Agricultural and Biosystems Engineering

College of Agriculture and

Related Sciences

University of Southeastern Philippines

Tagum-Mabini Campus,

Mabini, Davao de Oro

\section{Development and Optimization of Vermitea Vortex Brewer}

\author{
Kzyl Mae S. Albiso, Ryan M. Abenoja, \\ Roger C. Montepio, Ruel F. Tuyogon
}

\section{$\underline{\text { Abstract }}$}

Vermitea is a liquid mixture produced by aerated or non-aerated mixing of vermicast to water. The introduction of vortex brewers had made progress in producing vermitea in terms of faster brewing time. Commercial vortex brewer is expensive and is not locally available in the Philippines. This study aimed to develop and test a locally made vortex brewer. The effects of varying amounts of air flow rate (at T1 - 7.2 $\mathrm{L} \mathrm{min}^{-1}, \mathrm{~T} 2-14.4 \mathrm{~L}$ $\mathrm{min}^{-1}, \mathrm{~T} 3$ - 21.6 L min ${ }^{-1}$, T4-control/non-aerated) during the brewing process to the operating time, machine performance, and properties of produced vermitea were determined. The establishment of brewing time was conducted for 24 hours and the fastest time was identified for T3 and T4 at 12 hours while longer brewing time of 20 hours was identified for T1 and T2. It was observed that the brewing time was shorter for the brewer using highest air flow rate during brewing. The largest recovery was recorded by the brewer with the lowest flow rate (T1) which was $93.39 \%$. The brewing efficiency of the fabricated brewers was above the critical value. Also, the produced vermitea by all brewers has no foul odor which was an indication of proper aeration. The $\mathrm{pH}$ levels of the produced vermitea are all acidic, at a range of 6.19 to 6.86 , but are still within the acceptable range. An economic analysis indicates that the most economically feasible was brewer $\mathrm{T} 2$ with $7.2 \mathrm{~L} \mathrm{~min}^{-1}$ air flow rate.

Keywords: vermitea, organic concoctions, foliar fertilizer, brewing time 
Vermicomposting has become a pioneering scheme in the progress of organic farming in the Philippines. It utilizes earthworms (Lumbricidae) such as African Night Crawlers (Eudriluseugeniae) and associated microorganisms that act as catalysts for the production of organic soil amendment such as vermicast. It can either be implemented as a fertilizer or can be pre-mixed to the soil (development medium) before planting. Although vermicast is in strong form, soil and plant absorption of nutrients is smaller and it may take some time to see the effects. In order to accelerate its capacity to absorb nutrients, a new method of using vermicast was implemented. The cast is soaked in oxygenated, de-chlorinated water to create a nutrient- and microorganism-rich solution, allowing it to be incorporated into soil in its liquid state.

Vermitea is prepared either by non-aerated method (cheap but generally results in low oxygen conditions during tea extraction) or aerated method (maximizes oxygen during the extraction of compost) (Pant, 2011). Traditional or non-aerated brewing generally requires 3 days or 72 hours of constant brewing causing delays in manufacturing (Recycled Organics Unit, 2007). Meanwhile, aerated brewing uses an air pump to infuse air into the liquid solution to efficiently reduce brewing time by 20 to 24 hours. Aerated vermitea promotes good soil structure and provides aeration to soil, making it a favorable medium for better plant growth (Folds, 2018).

The newly designed commercial vortex-style brewer has a brewing time of 12-24 hours with a brewing capability of 15-30 liters. However, because of its high price, it is not economically feasible, particularly for small-scale farmers.

In this study, an innovative vortex-style vermitea brewing machine, which uses air pump and airstone, was developed. The prototype is electrically powered; the addition of water, molasses, and vermicast was manually done.

It was then modified according to the intent based on the current vermitea brewing system and was assessed using the information obtained after preliminary experiments. Most of its machine parts were sourced out from locally available components to augment fabrication expenses.

The study intends to address certain requirements of local farmers and vermitea manufacturers to make vermitea more cost-effective production-wise. It aims as well to reduce brewing time by using a cheaper machine without compromising the quality of vermitea produced.

The study in sum designed, constructed and evaluated the performance of the vortex-style vermitea brewing machine; determined the effects of varying amounts of air added (in L/min) on the brewing time, brewing efficiency, recovery, $\mathrm{pH}$ level, and dissolved oxygen (DO) content of the produced vermitea; and performed cost and benefit analysis. 


\section{Materials and Methods}

\section{Time and Place of study}

The study was conducted from January to June 2019 at the University of Southeastern Philippines, Tagum-Mabini Campus, Tagum Unit, Apokon, Tagum City, Davao del Norte Province.

\section{Research design and experimental layout}

The experiment was conducted with 4 treatments. One-way ANOVA was best suited for the experiment because there is only $l$ critical factor of operation to be considered.

The effects of the three variables to the $\mathrm{pH}$ level and dissolved oxygen content of the produced vermitea were determined in such a way that the design would allow an easy and practical test of the variables.

The rate of air flow rate based on the pump maximum rated value was considered as the factor in this study. Thus, below values were used as treatments:

$\mathrm{T} 1-7.2 \mathrm{~L} \mathrm{~min} \mathrm{~m}^{-1}$ air flow rate

$\mathrm{T} 2-14.4 \mathrm{~L} \mathrm{~min}^{-1}$ air flow rate

$\mathrm{T} 3-21.6 \mathrm{~L} \mathrm{~min} \mathrm{~m}^{-1}$ air flow rate

$\mathrm{T} 4$ - control (non-aerated brewing)

\section{Procedural framework}

Throughout the length of the research, the procedural structure described in Figure 1 was pursued to satisfy the set of goals. It began with conceptualizing the layout and then collecting the materials and manufacturing the components of the device and assembling the brewing machine. Data needed to manufacture the machine was gathered. Before proceeding to the final assessment, the brewers were pre-tested to determine the need for changes. 


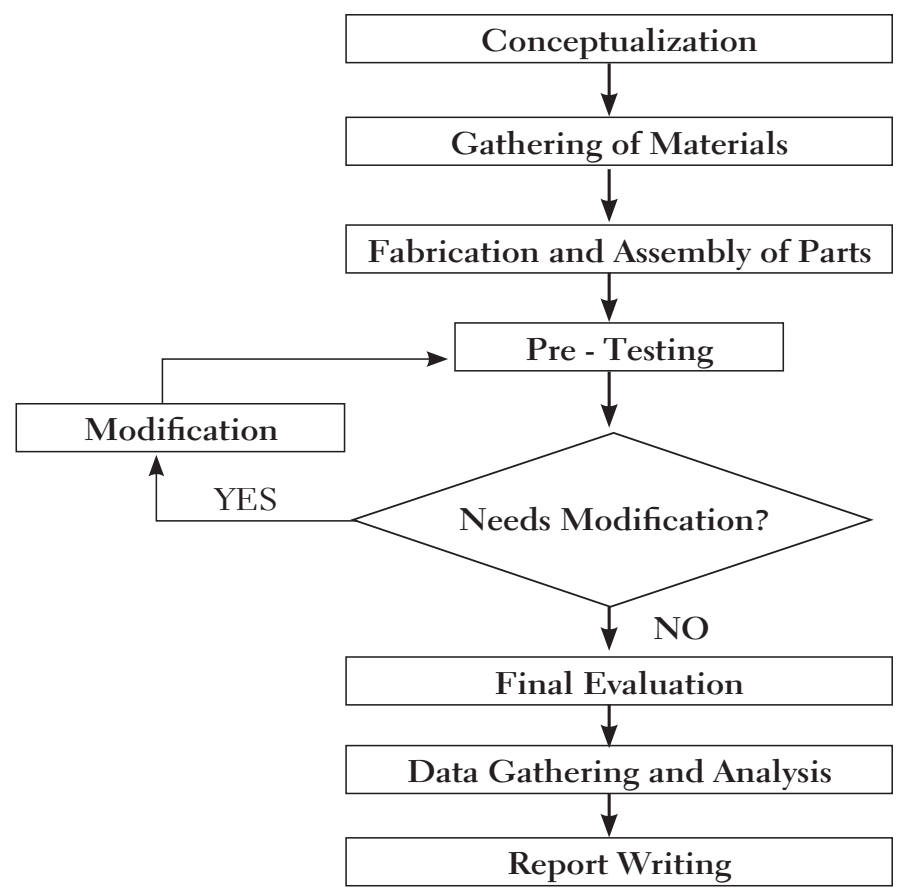

Figure 1. Procedural Framework

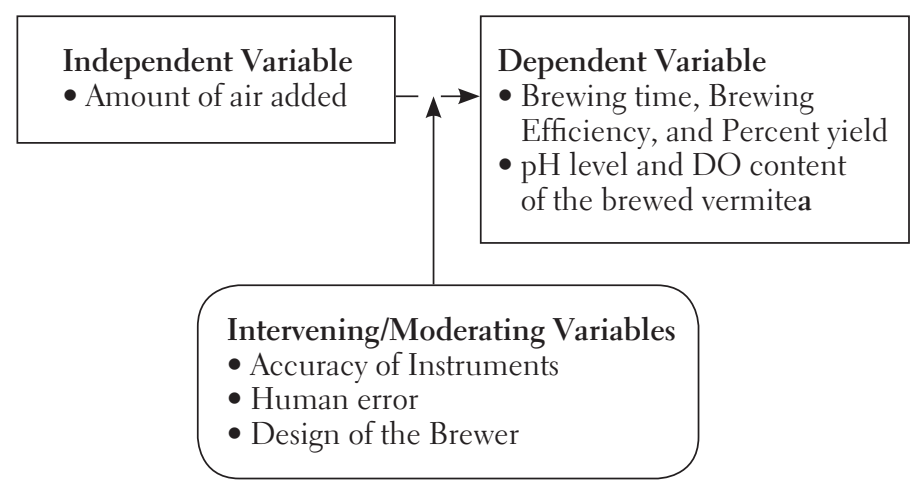

Figure 2. Conceptual Framework 


\section{Conceptual Design}

The machine brewing was based on the idea of starting a vortex water circulation by causing a large quantity of diffused air using an air pump and air rocks. By breaking down the air bubbles into much smaller pieces, the air stone will start an introduction of dissolved oxygen into the blend. The elevated quantity of diffused air will cause a quantity of water to shift upward and allow the water to flow through a vertically focused PVC pipe and escape through a horizontally focused PVC pipe with 2 taps made of right angle PVC pipe connectors facing in reverse directions. The water outlet layout is meant to allow a water stream in clockwise direction during brewing to gradually generate a vortex movement of the water.

The amount of air added to the mixture was varied and its effects to vermitea produced in terms of brewing efficiency, brewing time, percent yield, and $\mathrm{pH}$ level were determined. The vermicast was contained in a finely meshed black stocking that also acts as a filter to lessen the number of particles in the produced vermitea. The vermicast storage was held in the middle of the seal of the brewer and equipped and corrected with its distinct cap as shown in Figure 3. Throughout, the brewers were closed to minimize the loss of dissolved oxygen in the environment. The faucet on the container side acts as the reservoir for the item being brewed. Figure 4 shows an illustration of the brewer for 2 engines.

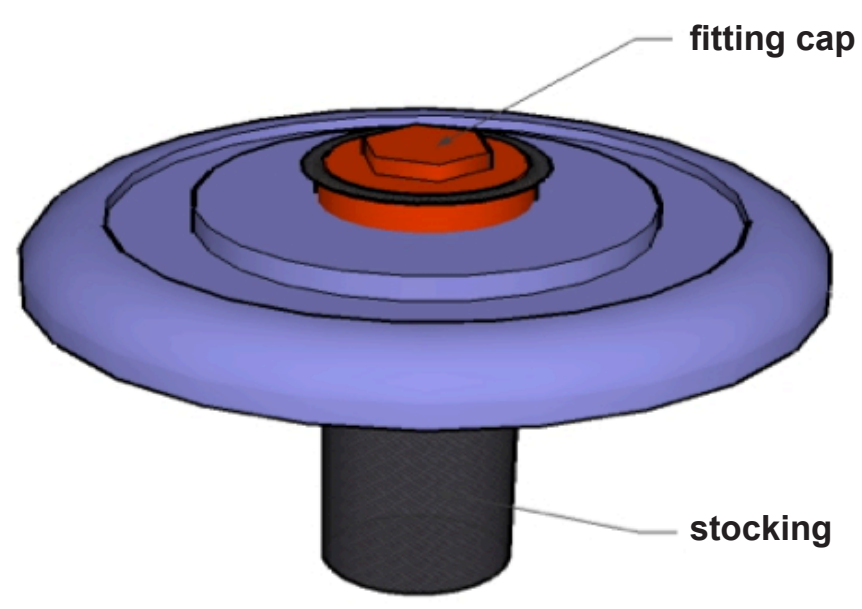

Figure 3. Illustration of the brewer cap 


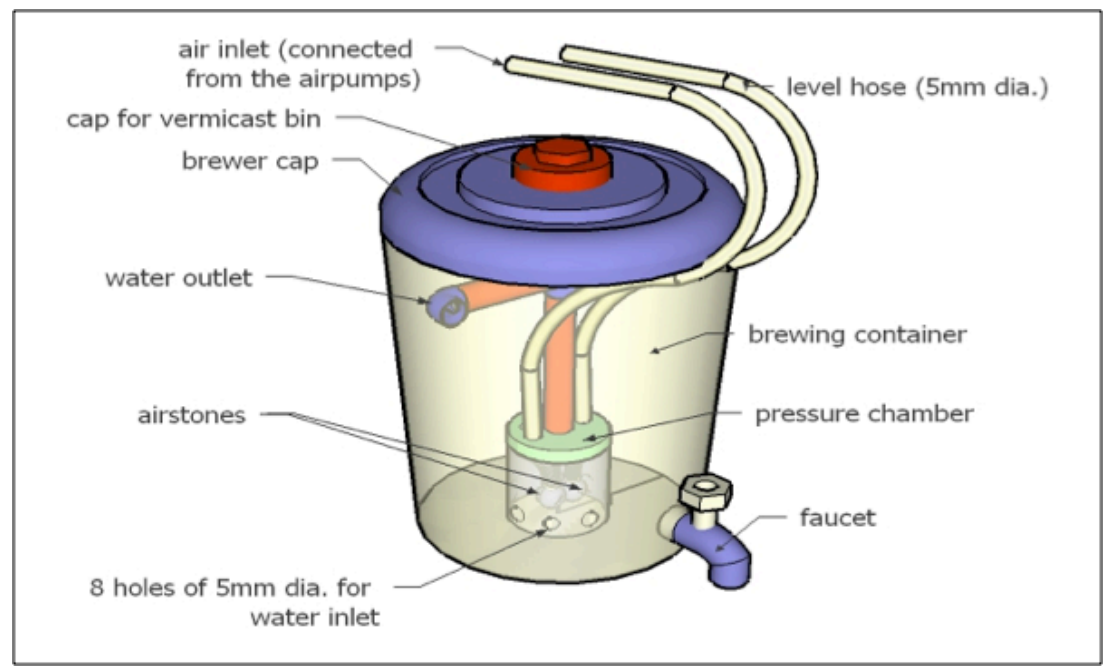

Figure 4. Vortex-style vermitea brewer for 2 air pumps

\section{General Procedure}

Procurement of materials. The brewer vortex vermitea intended for vermicast brewing carries a semi-cylindrical plastic container having a maximum capacity of 6.6 liters with a narrow cap allowing less air to escape during the brewing method into the adjacent area. Each air pump used holds a 3-watt rated power and a $3.6 \mathrm{~L} \mathrm{~min}^{-1}$ air flow rate. Stored vermicast bin content functioned as a filter. Air pumps, air stobes, and transparent hoses were purchased from a local pet shop while the vermicast was procured from USeP-Mabini Unit, Mabini, Davao de Oro Province, while the molasses were bought from Apokon Hardware, Apokon, Tagum City, Davao del Norte Province.

Fabrication and Assembly of Parts. The vermitea brewer was fabricated and assembled in Purok 4, Brgy. Magsaysay, Nabunturan, Davao de Oro. A rack was built to retain the 3 brewers during experiments for simple procedure and observation. The three semi-cylindrical containers used for the three brewers measured 9 inches, 8.5 inches and 7 inches in height, respectively. Five (5) mm $\varnothing$ level hoses were used for the air storage system as an air route with one end linked to the air pump outlet and the other end equipped with an air stone. A tiny plastic container with a height of $23 / 4$ inches and a diameter of $2 \frac{1}{2}$ inches was used as a pressure chamber as rush water flows up through a PVC pipe with a length of $43 / 4$ inches ( $20 \mathrm{~mm}$ outside $\varnothing$ ) positioned on top of the small plastic 
container. For the assembly of water outlet, a $20 \mathrm{~mm} \varnothing$ PVC T-connector was used to connect the 2 horizontally oriented pipes to the vertical pipe. The other ends of the 2 horizontal pipes were fitted with $20 \mathrm{~mm} \varnothing$ right-angle elbows and directed on the opposite. Detailed views of the pressure chamber and brewer assembly are shown in Figure 4 and Figure 5, respectively.

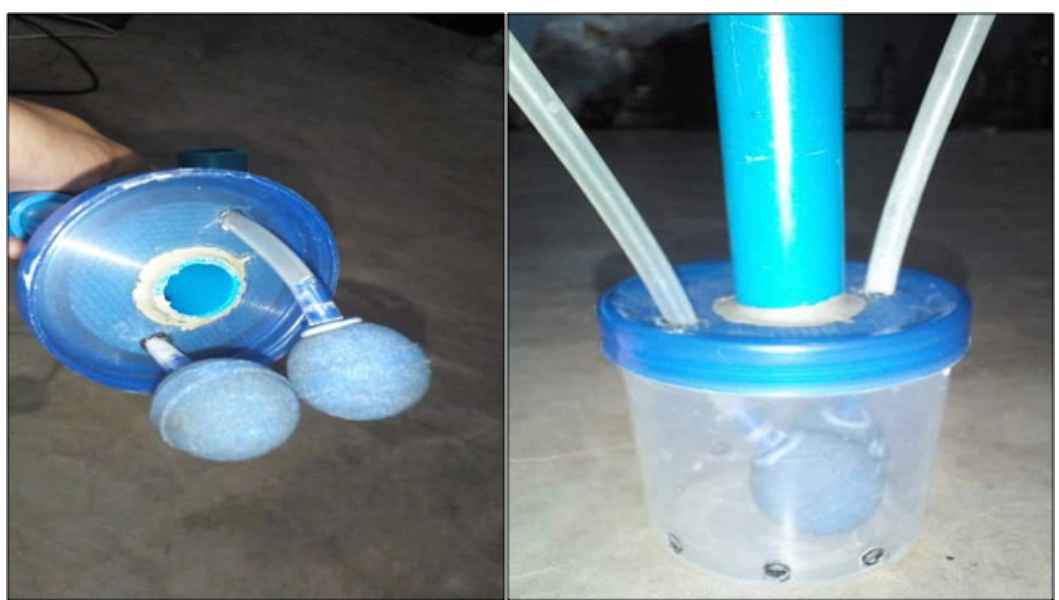

Figure 5. Fabrication and assembly of the pressure chamber

Preliminary Testing and Modification. Cracks, gaps, and any possible passage for leak were carefully checked. The tightness and stability of the joints and link points were likewise checked.

Final Testing. Using a beaker and graduated cylinders, each of the brewers was filled with 5.5 liters of tap water and the pumps were plugged into the power source and allowed to run for 10 minutes to aerate out possible chlorine contents in the water. The vermicast ( $270 \mathrm{~g}$ each) and molasses ( $50 \mathrm{~g}$ each) were then added and brewing time started afterward.

The same quantity of water is introduced for each replication and was mixed for 10 minutes. The same amount of vermicast was placed in the storage and was suspended on the water. After adding the same quantity of molasses, the brewing period began in order to aerate treatments and stirring was done for about 5-10 times an hour to control the whole process. The final testing was conducted at the Chemistry Laboratory of USeP-Tagum Campus. The final set-up is shown in Figure 6. 


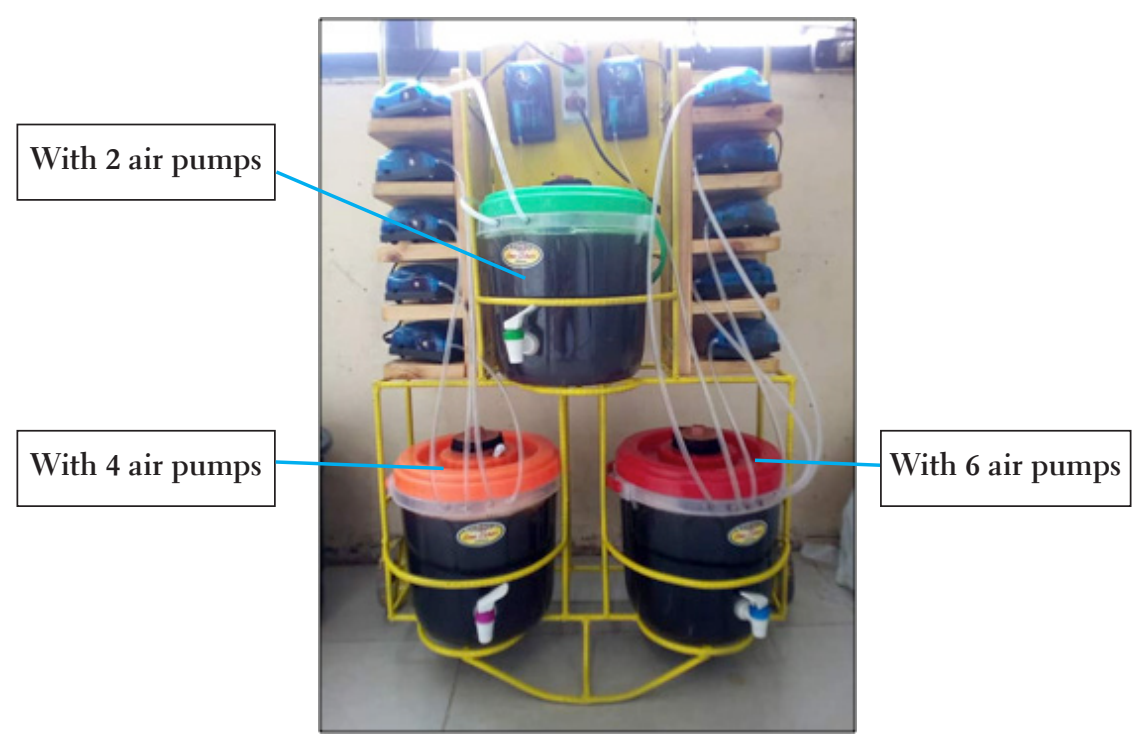

Figure 6. Set-up ready for testing

\section{Performance Evaluation}

Establishment of Brewing Time. The methodology used for establishing the brewing was according to the study of Cabaces, Landicho, Mauro, and Medrano (2015). The ideal brewing time was the period when the vermitea has more nematodes than protozoans in it. The determination of the number of protozoans and nematodes was done by taking $10 \mathrm{ml}$ vermitea samples every 4 hours of brewing using 4 types of brewers. The samples were then analyzed in the Analytical Laboratory of the University of Southeastern Philippines.

Evaluation of Brewing Efficiency. Brewing effectiveness is based on the amount of dissolved oxygen in the vermitea after 4 hours of brewing and at the end of the brewing cycle. It was measured using a dissolved oxygen meter. The effective limit must not be lower than $5-6 \mathrm{mg} / \mathrm{L}$.

Evaluation of Vermitea Recovery. Vermitea recovery is the ratio of the volume of the produced vermitea to the total volume of water, vermicast, and molasses used for brewing. The produced vermitea was decanted to a beaker to determine its volume.

$$
\text { Recovery }=\frac{(\text { Volume of Vermitea produced, } \mathrm{L})}{\left(\begin{array}{c}
\text { Total Volume of Water, vermicast } \\
\text { and molasses mixture, } \mathrm{L})
\end{array}\right.} \text { Equation } 1
$$


Evaluation of $\mathrm{pH}$ Level of vermitea. The produced vermitea of the 4 brewers was tested for the level of $\mathrm{pH}$ using a digital $\mathrm{pH}$ meter. Data on $\mathrm{pH}$ level was replicated 3 times for each of the samples.

\section{Statistical Analysis}

The statistical tool used in the study was One-Way Analysis of Variance (ANOVA) to test if there are no significant differences among the parameters of the study and to test the significant effect of the independent variable to the dependent variable. Additionally, Tukey Test analysis (using Minitab Software) was used to determine if the treatments have significant implication to the $\mathrm{pH}$ level and dissolved oxygen content of the produced vermitea.

\section{Results and Discussion}

\section{Brewing Time}

There are two common microorganisms present during the brewing of vermitea: nematodes and protozoans. A graphic illustration in Figure 7 (see next page) shows a comparison of the growth of nematodes during the establishment of brewing time from 09:13 AM to 09:13 AM of the next day. It shows that the brewing time was decreased with an increased amount of air added during the process. The peak number of nematodes occurred after 12 hours and 24 hours of brewing time for brewers $\mathrm{T} 3$ and $\mathrm{T} 4$, and $\mathrm{T} 1$ and $\mathrm{T} 2$, respectively. The time it took for the number of nematodes to peak is shorter for the brewer with the highest number of air pumps; the result was contrary to the pumps with smaller number of air pump. This was selected because brewing beyond the indicated time leads to depletion of nematodes and increased number of protozoans. As stated in the study of Cabaces et al. (2015), the vermitea is at its effective state when the population of nematodes is higher than the protozoans. 


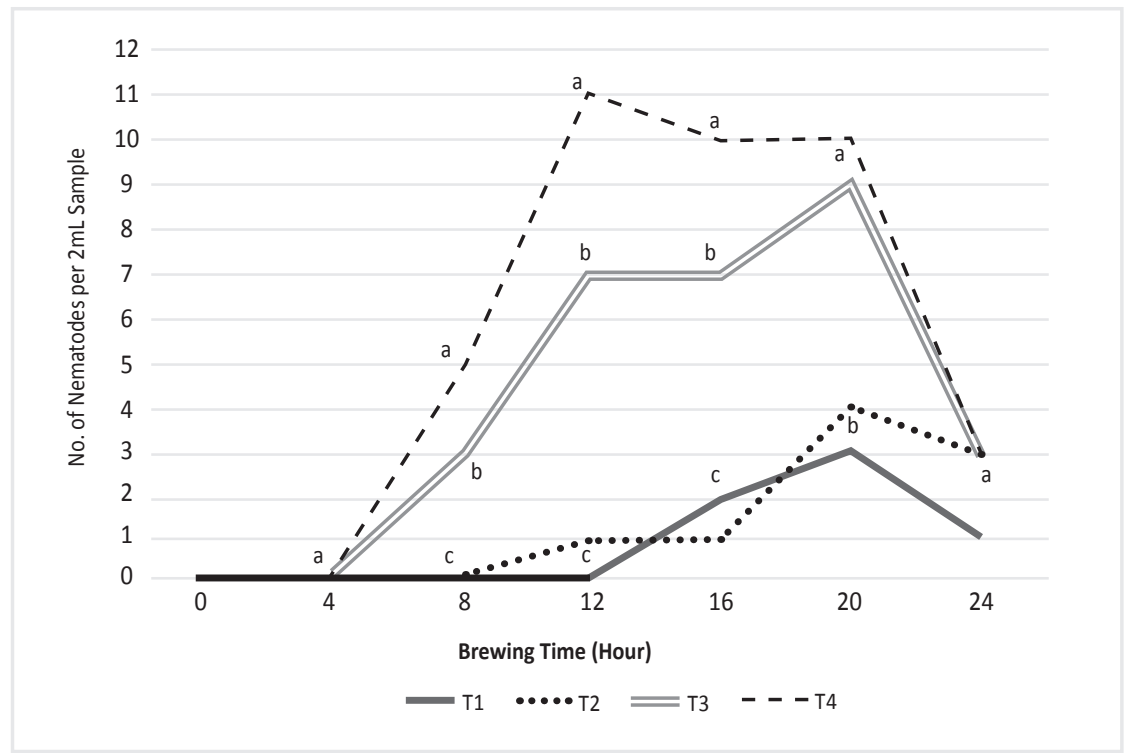

Figure 7. Comparison of the growth of nematodes during the brewing process

\section{Evaluation of Percent Yield}

It can be gleaned from Table 2 that the brewer with the highest percent yield of $93.39 \%$ is $\mathrm{T} 1$, followed by $\mathrm{T} 3$ with $91.25 \%$, T4 with $91.07 \%$, and $\mathrm{T} 2$ with the least percent yield with only $90.71 \%$. It can be deduced that the longer the brewing time and the least number of pumps, the higher the brewing yield.

Table 2. Percent yield of the 3 fabricated brewers and control brewer

\begin{tabular}{cllc}
\hline TREATMENT NO. & $\begin{array}{l}\text { Volume } \\
\text { of water with } \\
\text { vermicast and } \\
\text { molasses } \\
\text { (Liters) }\end{array}$ & $\begin{array}{l}\text { Volume } \\
\text { of Vermitea } \\
\text { produced }\end{array}$ & Percent Yield \\
\hline T1 & 5.6 & (Liters) & $\mathbf{( \% )}$ \\
T2 & 5.6 & 5.23 & 93.39 \\
T3 & 5.6 & 5.08 & 90.71 \\
T4 & 5.6 & 5.11 & 91.25 \\
\hline
\end{tabular}




\section{Evaluation of Brewing Efficiency}

Analysis of variance shows that there is no significant difference among T1, $\mathrm{T} 2$, and $\mathrm{T} 3$ (Table 3). The dissolved oxygen of the above mentioned treatments was in the range of good vermitea OF 5-6 mg/l (Cabaces et al. 2015).

The results of the brewing process show that the 3 brewers were efficient and that the vermiteas were properly aerated since the dissolved oxygen are within the range of $5-6 \mathrm{mg} / \mathrm{l}$. It was also observed that the produced vermitea of T1, T2, and T3 smelled sweet and pleasant while T4 had a strong odor similar to that of vinegar. The presence of foul smell in vermitea was another indication of improper brewing (Cabaces et al. 2015).

Table 3. Mean dissolved oxygen content of the vermitea obtained from brewers $\mathrm{T} 1, \mathrm{~T} 2, \mathrm{~T} 3$, and $\mathrm{T} 4$

\begin{tabular}{cl}
\hline Treatment & Mean \\
\hline T3 & $5.9843 \mathrm{a}$ \\
T2 & $5.4843 \mathrm{a}$ \\
T1 & $5.4100 \mathrm{a}$ \\
T4 & $4.3214 \mathrm{~b}$ \\
\hline
\end{tabular}

Means that do not share a letter are significantly different.

Grouping Information Using the Tukey Method and 95\% Confidence

\section{Effects on pH Level}

The $\mathrm{pH}$ level was obtained using a digital pH meter. Analysis of Variance, shown in Table 4 (next page), revealed a significant difference among treatment means. The $\mathrm{pH}$ level of the vermitea produced through vortex-style brewers, ranging from 6.19 to 6.86 , are less acidic compared to the vermitea produced using non-aerated brewing, which ranged between 4.85 to 4.86 in the $\mathrm{pH}$ scale. Since the soil $\mathrm{pH}$ range for most plants should be between 6.0 and 7.0, the vermitea's $\mathrm{pH}$ level can be lowered by diluting in water before application. 
Table 4. Mean pH level of the vermiteas obtained from brewers T1, T2, T3, and T4

\begin{tabular}{cl}
\hline Treatment & Mean \\
\hline T2 & $6.85000 \mathrm{a}$ \\
T1 & $6.6367 \mathrm{~b}$ \\
T3 & $6.2100 \mathrm{c}$ \\
T4 & $4.85333 \mathrm{~d}$ \\
\hline
\end{tabular}

Means that do not share a letter are significantly different.

Grouping Information Using the Tukey Method and 95\% Confidence

According to Miller (2016), maintaining a proper $\mathrm{pH}$ level is important because elements like aluminum $(\mathrm{Al})$, iron $(\mathrm{Fe})$ and manganese $(\mathrm{Mn})$ can cause plant toxicity in acid soils with a $\mathrm{pH}$ level of below 4.5. Uptake of nitrate (NO3 -) by plants is best at a lower $\mathrm{pH}$, while $\mathrm{NH} 4+$ is absorbed more efficiently at a neutral pH. Optimum $\mathrm{P}$ availability is at $\mathrm{pH}$ 6.5. Below 6.5, $\mathrm{P}$ becomes insoluble $\mathrm{Al} / \mathrm{Fe}$ minerals, in other words, it absorbs to oxides and clay. Above 6.5, P bonds with $\mathrm{Ca}$ to form solid minerals similar to Ca-phosphate fertilizers. Potassium, $\mathrm{Ca}$ and $\mathrm{Mg}$ are less available in acid soils because they have been leached out, not necessarily due to solubility issues. Micronutrients such as Boron (Bo), Zinc (Zn), Manganese (Mn), Iron (Fe), and Copper (Cu) decrease in availability as $\mathrm{pH}$ rises.

\section{Effect on NPK content}

Laboratory analysis (Table 5) of the cast revealed Tl had the highest $\mathrm{N}$ content and $\mathrm{T} 4$ had the lowest. All aerated brewers (T1-T3) had higher $\mathrm{K}_{2} \mathrm{O}$ content than the control. Tl had the highest NPK content of $0.1 \%$ (higher than that of Cabaces et al. at $0.033 \%$ ), however this is dependent on the vermicast used. 
Table 5. Result of the Laboratory Analysis

\begin{tabular}{cccc}
\hline Treatment & Total $\mathbf{N}$ & $\mathbf{P}_{2} \mathbf{O}_{5}$ & $\mathbf{K}_{2} \mathbf{O}$ \\
\hline T1 & 0.06 & BDL & 0.04 \\
T2 & 0.007 & BDL & 0.04 \\
T3 & 0.005 & BDL & 0.04 \\
T4 & 0.003 & BDL & 0.03 \\
\hline
\end{tabular}

\section{Benefit-Cost Analysis}

Table 6 shows the benefit-cost ratio of the 3 vortex brewers, Tl has the highest BCR even though the benefits derived from its NPK content were not valued. Also, T1 has the lowest energy cost and same with T2 took 20 hours to brew. T4 was not included in the analysis because the produced tea is very acidic and has very low total NPK content.

Table 6. Benefit-Cost Ratio of the Brewers

\begin{tabular}{c|c|c|c|c|c|c}
\hline Year & Total Costs & Benefits & Net Benefits & $\begin{array}{l}\text { Discount } \\
\text { Factor (6\%) }\end{array}$ & $\begin{array}{c}\text { Present } \\
\text { Value }\end{array}$ & BCR \\
\hline 1 & PhP 20,000.00 & $\operatorname{PhP~15,000.00}$ & $\operatorname{PhP~(5,000.00)}$ & 1 & $\operatorname{PhP~(5,000.00)~}$ & 0.75 \\
2 & $\operatorname{PhP~3,000.00}$ & $\operatorname{PhP~21,000.00}$ & $\operatorname{PhP~18,000.00}$ & 0.87 & $\operatorname{PhP~15,652.17~}$ & 1.471154 \\
3 & $\operatorname{PhP~3,000.00}$ & $\operatorname{PhP~21,000.00}$ & $\operatorname{PhP~18,000.00}$ & 0.76 & $\operatorname{PhP~13,610.59~}$ & 1.975304 \\
\hline & & & & \multicolumn{3}{c}{ NPV = PHP 24,262.76 } \\
\hline
\end{tabular}




\section{Summary}

The research was performed to design and build a vermitea vortex brewer and to determine the optimum pump air flow rate to be used in the brewing method. Furthermore, the performance of the brewer in terms of brewing efficiency, recovery, $\mathrm{pH}$ and dissolved oxygen in the tea was determined. Four brewers were manufactured with built-in air pumps and air stones that provide the system with a large quantity of diffused air. The factor involved in this study was the varying amounts of pump air flow rate based on pump specification: $\mathrm{T} 1-7.2 \mathrm{~L} \mathrm{~min}^{-1}, \mathrm{~T} 2-14.4 \mathrm{~L} \mathrm{~min}^{-1}, \mathrm{~T} 3-21.6 \mathrm{~L} \mathrm{~min}^{-1}$, and $\mathrm{T} 4$ - non-aerated. The testing of the vortex-style brewers was conducted at the Chemistry Laboratory of the University of Southeastern Philippines, Tagum Unit, Apokon, Tagum City, Davao del Norte Province.

The brewers were filled equally with 5.5 liters of tap water, 270 grams of vermicast and 50 grams of molasses. For the control, a distinct set-up was created for a brewer with frequent manual stirring. The brewing period was focused on the microscopic analysis of microorganism behavior discovered on the tea. After every 4 hours of brewing, samples were collected and immediately analyzed.

The designed and fabricated vortex-style vermitea brewer with a maximum of 6-liter capacity can initiate a vortex motion of water which aids in the improved aeration and equal distribution of dissolved oxygen during the brewing process. $\mathrm{T} 1$ and T2 had longer brewing or operating time (20 hours) while T3 and T4 had shorter time (12 hours). Brewing beyond 12 hours leads to depletion of nematodes and increased number of protozoans

Recovery was highest at $93.39 \%$ for $\mathrm{Tl}$, followed by T3 with $91.25 \%$, T4 with $91.07 \%$, and $\mathrm{T} 2$ had the lowest recovery with $90.71 \%$. The brewing of the machines excluding the control was efficient because the dissolved oxygen content is within the acceptable values which are from $5-6 \mathrm{mg} / \mathrm{L}$ of DO. Additionally, no foul smell was observed.

In terms of $\mathrm{pH}$ level, the produced vermiteas were acidic. For the fabricated brewers, the $\mathrm{pH}$ level ranged from 6.19 to 6.86 whereas for the control, the $\mathrm{pH}$ was comparatively lower in the range of 4.85 to 4.86 . The economic analysis revealed a benefit-cost ratio (BCR) of 1.95, 1.59 and 1.38 for T1, T2, T3. 


\section{Conclusion}

Vortex brewers were successfully developed; they were evaluated as having the capacity of optimizing brewing time. Based on observation, the brewers were able to create a vortex action during the brewing process. For faster brewing ( 12 hours), the optimum airflow rate to be used should be $21.6 \mathrm{~L} \mathrm{~min}{ }^{-1}$. The study was able to show successful reduction of brewing time without compromising the quality of the vermitea.

The variation in the air flow rate used for the brewing process can significantly affect the $\mathrm{pH}$ level and dissolved oxygen of the produced vermitea. The fabricated brewers have produced a less acidic vermitea compared with the control brewer. All were economically feasible as indicated in the economic analysis.

\section{Recommendation for further studies}

The researchers propose further inquiry into the impacts of air variability introduced during the brewing method on the micronutrient and population of other microorganisms present in the tea. Another study may be conducted to determine the life span of useful microorganisms in the tea after the brewing process. Furthermore, study on the effect of different vermicast substrates to the quality of vermitea produce can also be conducted. 


\section{References}

Cabaces, D., Landicho, J., Mauro, A., \& Medrano, M. (2015). Development of a Vermi Tea Brewing Machine. Asia Pacific Journal of Multidisciplinary Research, 3(4). http:// www.apjmr.com/wp-content/uploads/2015/10/APJMR-2015-3.4.3.07.pdf

Folds, E. (2018). Compost Tea. The Canadian Journal of Microbiology Ultimate Guide to Brewing Compost Tea. Retrieved from: https://medium.com/@evanfolds/theultimate-guide-to-brewing-compost-tea-8ddeb4622b9e. Date Retrieved: January 23, 2019

Miller, J.O. (2016). Soil pH Affects Nutrient Availability. The University of Maryland Extension. Fact Sheet FS-1054. Retrieved from: https://drum.lib.umd.edu/bitstream/ handle/1903/18519/FS1054\%20Soil\%20pH\%20and\%20Nutrient\%20Availbility.pdf. Date Retrieved: June 10, 2019

Pant, A., Radovich, T., Hue, N. and Arancon, N. (2011). Effects of Vermicompost Tea (Aqueous Extract) on Pak Choi Yield, Quality, and on Soil Biological Properties. Compost Science \& Utilization Vol. 19, No. 4, 279-292.

Recycled Organics Unit. (2017). Overview of Compost Tea Use in New South Wales. 2nd Ed. Sydney: The University of New South Wales. 